\title{
Pelatihan Da'i Antikorupsi bagi Mubaligh-Mubalighah Terdampak Physical Distancing Akibat Pandemi Covid-19 di Kelurahan Prenggan, Kotagede, Yogyakarta
}

\author{
Suyadi ${ }^{1}$, Waharjani $^{2}$, Sumaryati ${ }^{2}$, Trisna Sukmayadi ${ }^{2}$ \\ 1, 2 Universitas Swadaya Gunung Jati, Indonesia
}

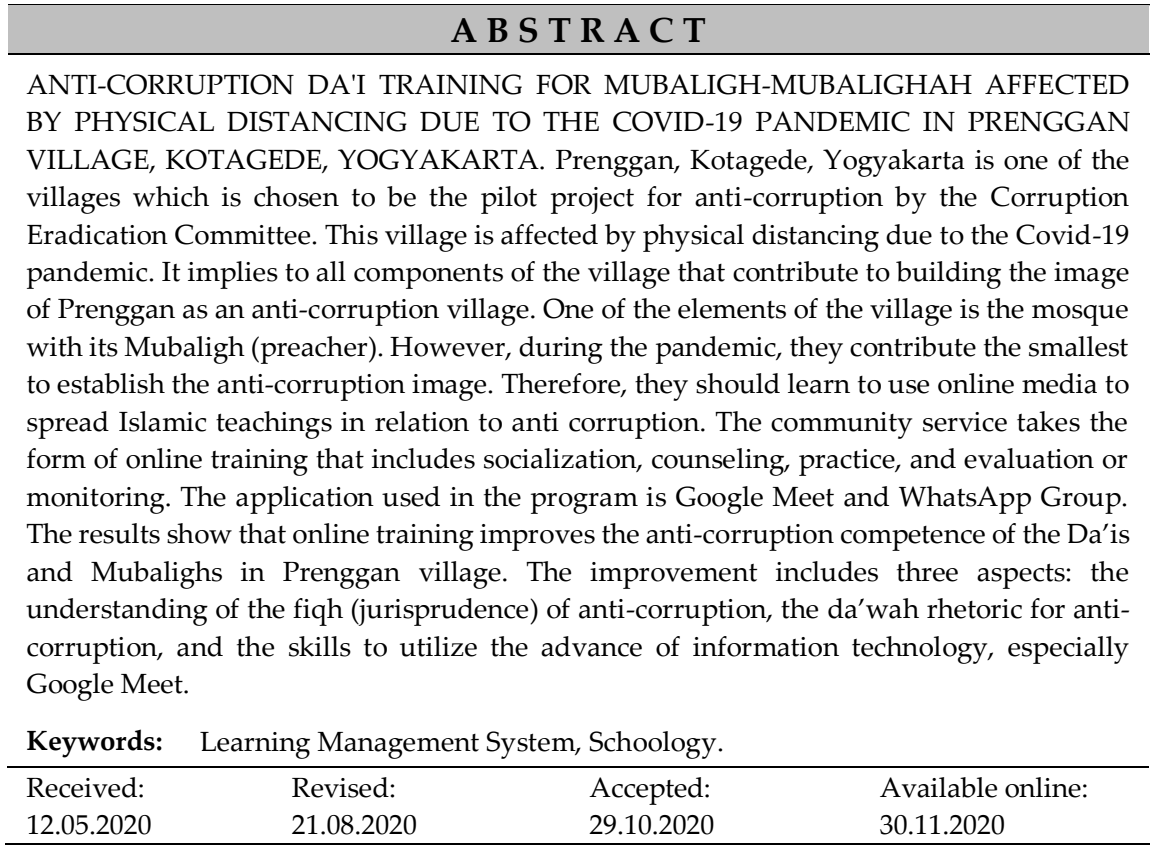

Suggested citation:

Suyadi, Waharjani, Sumaryati, \& Sukmayadi, T. (2020). Pelatihan da'i antikorupsi bagi mubalighmubalighah terdampak physical distancing akibat pandemi covid-19 di Kelurahan Prenggan,

Kotagede, Yogyakarta. Jurnal Pengabdian Pada Masyarakat, 5(4), 1051-1064. https://doi.org/10.30653/002.202054.522

Open Access I URL: http://ppm.ejournal.id/index.php/pengabdian/article/view/522

\footnotetext{
${ }^{1}$ Corresponding Author: Program Studi Magister Pendidikan Agama Islam Program Pascasarjana Universitas Ahmad Dahlan; Jl. Pramuka No. 42, Sidikan, UH Yogyakarta, Indonesia. Email: suyadi@fai.uad.ac.id
} 


\section{PENDAHULUAN}

Pandemi Covid-19 telah menyebar ke 215 negara (Sohrabi et al., 2020), termasuk Indonesia dan Kelurahan Prenggan Kotagede Yogyakarta di dalamnya. Keluarahan Prengan merupakan satu-satunya desa antikorupsi di Indonesia yang sekarang terdampak phisical distancing akibat pandemi Covid-19 (Freedman, 2020). Desan ini dipilih Komisi Pemberantasan Korupsi (KPK) sebagai desa antikorupsi sejak tahun 2013 (Rabi \& Nurhidayati, 2018) karena memiliki sejumlah nilai luhur seperti gotongroyong, guyub, dan jujur yang tetap lestari di era modern ini (Waskito \& Pambudi, 2018). Desa Antikorupsi menarik perhatian masyarakat luas karena saat ini lebih dari 900 Kepala Desa menjadi tersangka kasus korupsi dana desa (Rahman et al., 2018), pasca diberlakukannya UU No. 6 Tahu 2014 Tentang Desa (Mulyono, 2014). Meskipun menjadi desa antikorupsi, tetapi dalam situasi terdampak phisical distancing akibat pandemi Covid-19 desa ini tidak lepas dari potensi perilaku koruptif yang dilakukan oleh oknum tak bertanggung jawab. Hal ini diindikasikan langkanya masker dan hand sanitizer serta masih banyaknya warga yang keluar rumah di tengah kondisi physical distancing (Jati \& Putra, 2020).

Kelurahan Prenggan ditetapkan KPK sebagai desa Antikorupsi sejak 2013, namun program-program kegiatan KPK mengalami stagnasi pada tahun 2017. Dalam studi analisis pada 5 September 2019, Lurah Prenggan menyatakan bahwa program-program KPK di kelurhan Prenggan selama 4 tahun (2013-2017) masih sangat terbatas karena hanya menyentuh komunitas pendidikan anak dalam keluarga, belum menyentuh komunitas yang lebih luas, seperti Karangturuna, Remaja masjid, Ta'mir masjid, dan lain sebagainya. Hal ini diperkuat oleh pernyatan ER, Ketua Relawan Antikorupsi Prenggan, bahwa kegiatan KPK saat ini hanya mejadi kegiatan insidental sekunder, bukan agenda primer. Program kegiatan antikorupsi dalam keluarga biasanya dilakukan dalam bentuk pembacaan cerita atau kisah (Suyadi, 2018a), dan maksimal di lembaga-lembaga pendidikan anak usia dini (Suyadi, 2018b).

Analisis situasi ini pada akhirnya mengerucut pada kegelisahan semua pihak, yakni minimnya peran Da'i atau Mubaligh dan Ta'mir Masjid dalam pencegahan korupsi. Analisis ini diperkuat dengan fakta bahwa 100\% warga Prenggan adalah Muslim dengan tingkat keta'atan beribadah yang tinggi dan menjadikan masjid sebagai basis gerakan sosial (Suyadi, et al., 2019). Namun selama ini masjid belum dilibatkan sama sekali dalam pembangunan Prenggan sebagai desa antikorupsi.

Oleh karena itu, masjid berserta para Da'i di dalammya harus terlibat lebih aktif dalam pencegahan korupsi (Suyadi, 2019; Suyadi, et al, 2019). Perlu ditegaskan bahwa meskipun Islam telah mengajarkan iman dan taqwa kepada Tuhan Yang Maha Esa, namun da'wah anti korupsi masih relevan mengingat banyak umat beragama yang berperilaku koruptif (Tom \& Bamgboye, 2017), (Warf, 2016). Argumen ini sekaligus menegaskan bahwa jika orang yang sudah ta' at beragama saja masih korupsi, (Xixiong X., Yaoqin Li., Xing L., 2017), tentu mereka yang tidak ta'at beragama lebih beresiko melakukan korupsi.

Berdasarkan analisis situasi tersebut, Tim Pengadi menawarkan solusi terstruktur dan sistematis kepada Lurah Penggran beserta para Mubaligh untuk diselenggarakan pelatihan Da'i antikorupsi. Solusi terstruktur dan sistematis ini berdasarkan potensi Tim Pengabdi yang merupakan juru da'wah sekaligus Penyuluh antikorupsi dari KPK. 
Sejumlah hasil penelitian Tim Pengabdi tentang antikorupsi dan manajemen dakwah juga akan diterapkan dalam pelatihan ini, seperti kesalehen konstitusional (Suyadi, et al., 2020; Suyadi, et al., 2019), manajemen masjid (Waharjani, 2016), pelatihan imam dan khatib (Waharjani, 2018a), serta pelatihan mubaligh (Waharjani, 2018b). Dengan demikian solusi ini jauh lebih transformatif dari pada sekadar kajian antikorupsi dalam Islam secara normatif (Romziatussa'adah, 2014). Mempertimbangkan kompetensi Tim Pengusul dan hasil-hasil penelitian yang akan diterapkan, Lurah Prenggan dan para Mubaligh menyetujui solusi terstruktur dan sistematis yang ditawarkan tersebut. Gambar 1a dan $1 \mathrm{~b}$ menunjukkan bahwa analisis situasi oleh Tim Pengabdi bersama Lurah Prenggan dan perkumpulan Ta'mir Masjid se kelurahan Prenggan.

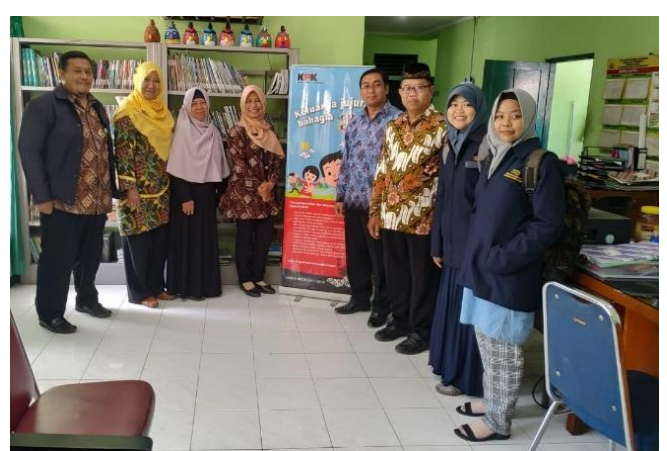

Gambar 1a. Analisis situasi bersama Lurah Prenggan

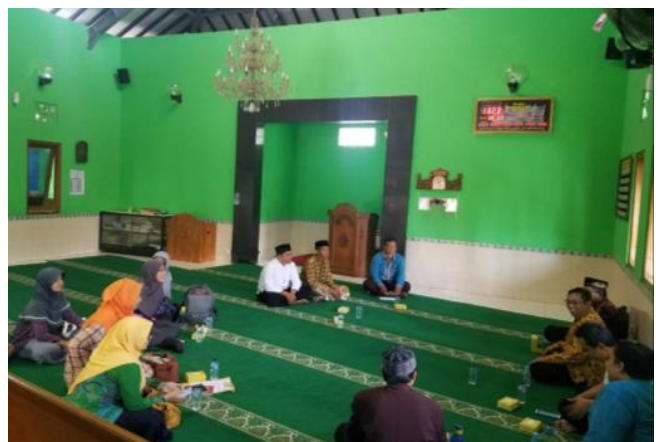

Gambar 1b. Analisis situasi bersama Ta'mir Masjid Prenggan

Gambar 1a merupakan analisis situasi awal bersama Lurah Prenggan yang telah menghasilkan kesepakatan untuk melibatkan Ta'mir Majid, Da'i atau Mubaligh dalam pengembangan desa antikoruspi. Gambar $1 \mathrm{~b}$ menunjunjukkan analisis situasi lanjutan bersama Perkumpulan Ta'mir Majid se Kelurahan Prenggan untuk menyelenggarakan pelatihan Da'i antikorupsi. Analisis situasi ini menghasilkan kesepakatan bahwa pelatihan da'i antikorupsi bagi Mubaligh-Mubalighah terdampak Physical Distancing akibat pandemi Covid-19 dilaksanakan secara daring, menggunakan aplikasi utama "Google Meet" dan aplikasi pendukung "WhatsApp Group."

Pelatihan Da'i atau Mubaligh antikorupsi bukanlah hal yang baru sama sekali. Kamal dan Arifin telah memulai penelitian normatif tentang hukum doktrinal yang menjelaskan peran masyarakat sipil dalam pencegahan korupsi (Kamal \& Arifin, 2019). Upaya yang lebih serius dilakukan oleh Pimpinan Pusat Muhamamdoyah dengan membuka program Madrasah Antikorupsi (Sukoco, 2015). Penelitian Asroni dan Yusup juga telah menginisiasi pembelajaran antikorupsi di Pesantren (Asroni \& Yusuf, 2016). Universitas Gadjah Mada juga telah mempelopori sekolah integritas di SMA N2 Yogyakarta (Susanti, Mochtar, Madril, \& Ravizki, 2016).

Namun demikian, penelitian dan atau pemberdayaan masyarakat yang secara khusus mengembangkan kompetensi para Da'i atau Mubaligh agar setiap dakwahnya membawa pesan nada dakwah antikorupsi belum banyak dilakukan. Pengabdian dan atau penelitian tentang desa antikoruspi di Kelurahan Prenggan sendiri baru terdapat dua tema dan keduanya fokus pada pendidikan keluarga, yakni penelitian M rabi'e dan Nurhidayati serta Waskito dan Pambudi (Rabi \& Nurhidayati, 2018), (Waskito \& Pambudi, 2018). Dengan demikian, pelatihan Da'i antikorupsi bagi Mubaligh- 
Mubaligha terdampak physical distancing akibat pandemi Covid-19 belum pernah dilaksanakan.

Oleh karena itu, pelatihan Da'i antikorupsi bagi Mubaligh/ Mubalighah terdampak physical distancing akibat pandemi Covid-19 dapat mengisi celah pengabdian masyarakat yang selama ini belaum dilakukan. Hasil pengabdian ini disamping meningkatkan kompetensi Da'i antikorupsi, juga menjadi model atau prototype da'wah antikorupsi. Pelatihan ini dapat memberi bekal kompetensi pada para Da'i dan Da'iyah atau Mubaligh dan Mubalighah antikorupsi, sehingga setiap Da'i atau Mubalihg berda'wah, maka dakwanya akan membawa pesan antikoruspi. Atas dasar ini, akan terjadi arus baru pencegahan korupsi berbasis masjid yang dipelopori oleh para Da'i-da'iyah atau Mubaligh-Mubalighah.

\section{METODE}

Metode pelaksanaan pengabdian masyarakat ini adalah pelatihan daring, karena mitra para Da'i sedang terdampak physical distancing. Adapun aplikasi yang digunakan adalah Google Meet didukung dengan WhatsApp Group. Google meet merupakan aplikasi utama dalam proses pelatih, sedangkan WhatsApp Group hanya digunakan sebagai aplikasi pendukung untuk mempermudah komunikasi (Jain \& binti Abd Rahman, 2016; Boyinbode et al., 2017). Sinergi dan kombinasi kedua aplikasi ini menjadi trend pembelajaran daring di era milenial (Suyadi \& Widodo, 2019; Atabekova et al., 2015) dan terbukti efektif dari pada aplikasi lainnya seperti Zoom, Skype, Google Classroom, dan lain sebagainya (Dharma et al., 2017).

Selanjutnya, dipilihnya metode pelaksanaan pelatihan karena pengabdian ini ingin meningkatakan keterampilan dakwah antikorupsi bagi para Da'i atau Mubaligh di masjid-masjid Kelurahan Prenggan. Dalam mencapai tujuan ini, metode pelatihan banyak meiliki keunggulan dari pada metode pengabdian lainnya seperti penyuluhan, sosialisasi, konsultasi, mediasi, simulasi dan lain sebagainya. Di dalam pelatihan itu sendiri sudah mencakup sosialisasi, penyuluhan, dan simulasi. Dalam konteks penelitian, pelatihan dalam pengabdian masyarakat seperti ini termasuk dalam kategori partisipatory action research (PAR), yakni peneliti atau pengabdi berperan aktif dan berkolaborasi dengan masyarakat atau kelompok sasaran (Ahmad Muhtadi, 2017), (Feni Qoriroh, 2016).

Seting lokasi pengabdian kepada masyarakat ini adalah Kelurahan Prenggan Kotagede Yogyakarta. Kelurahan Prenggan dipilih sebagai seting pengabdian karena memiliki modal sosial (Yeary et al., 2012) yang tidak dimiliki oleh kelurahan lainnya, yakni Desa Antikorupsi. Di samping itu, Prenggan juga memiliki aset spiritual, yakni paguyuban Mubaligh-Mubalighah Prenggan yang belum tentu dimiliki oleh Kelurahan lainnya (Verter, 2003), (Urban, 2005). Subyek pengabdian masyarakat ini adalah para Da'i-da'iyah atau Mubaligh-Mubalighoh sejumlah 18 orang yang tergabung dalam Paguyuban Mubaligh-Mubalighah Prenggan. Usia subyek pelatihan antara 40-60 tahun dengan pengalaman dakwah minimal lebih dari 5 tahun.

Selanjutnya, prosedur pengabdian mencakup empat langkah, yakni sosialisasi, penyuluhan, demonstrasi atau implementasi, dan evaluiasi. Pertama, sosialisasi pelatihan Da'i-Da'iyah antikorupsi. Sosialisasi dilakukan kepada para Ta'mir Masjid di 
lingkungan Prenggan agar menggerakkan Mubaligh dan Mubalighah agar mendaftarkan serta mengikuti pelatihan Da'i antikorupsi. Kedua, penyuluhan Da'ida'iyah antikorupsi. Penyuluhan dilakukan kepada para Da'i-Da'iyah yang tergabung dalam paguyuban Mubaligh-Mubalighah Prenggan. Bentuk kegiatan penyuluhan ini adalah pelatihan daring tentang fikih antikorupsi. Ketiga, implementasi atau demonstrasi dakwa antikorupsi. Kegiatan ini berupa praktik dakwah (kultum/ khutbah) bermuatan antikoruspi. Para Mubaligh-Mubalighah diminta membuat materi kultum atau khutbah tentang Fikih Antikorupsi dan mempraktikkannya. Keempat, evaluasi dan monitoring. Evaluasi dilakukan Tim Pengabdi bersama para MubalighMubalighah yang mengikuti pelatihan Da'i-Da'iyah antikorupsi. Evaluasi ini dimaksudkan untuk menemukan kelemahan dan kekurangan sehingga menjadi bahan perbaikan di masa mendatang. Tabel 1 berikut ini merupakan rangkaian kegiatan pelatihan da'wah antikorupsi.

Tabel 1. Metode pelaksanaan pelatihan Da'i Antikorupsi

\begin{tabular}{|c|c|c|c|c|}
\hline No & $\begin{array}{l}\text { Prosedur } \\
\text { Pengabdian }\end{array}$ & Waktu & $\begin{array}{l}\text { Kondisi } \\
\text { Masyarkat }\end{array}$ & Kegiatan \\
\hline \multirow{4}{*}{1} & \multirow{4}{*}{ Analisis Situasi } & $\begin{array}{l}5 \text { September } \\
2019\end{array}$ & Normal-Aktif & $\begin{array}{l}\text { Analisis situasi bersama } \\
\text { Lurah Prengan }\end{array}$ \\
\hline & & $\begin{array}{l}9 \text { September } \\
2019\end{array}$ & Normal-Aktif & $\begin{array}{l}\text { Analisis situasi bersama Tim } \\
\text { Relawan Antikorupsi } \\
\text { Prengan }\end{array}$ \\
\hline & & $\begin{array}{l}3 \text { November } \\
2019\end{array}$ & Normal-Aktif & $\begin{array}{l}\text { Finalisasi program dan } \\
\text { persetujuan kegiatan oleh } \\
\text { Lurah Prenggan }\end{array}$ \\
\hline & & $\begin{array}{l}30 \text { November } \\
2019\end{array}$ & Normal-Aktif & $\begin{array}{l}\text { Finalisasi program bersinergi } \\
\text { Tim Relawan Antikorupsi } \\
\text { Prengan }\end{array}$ \\
\hline \multirow{3}{*}{2} & \multirow{3}{*}{ Sosialisasi } & 6 Maret 2020 & Normal-Aktif & $\begin{array}{l}\text { Sosialisasi awal bersama } \\
\text { Ta'mir Masjid Firman } \\
\text { Prenggan }\end{array}$ \\
\hline & & 9 Maret 2020 & Normal-Aktif & $\begin{array}{l}\text { Sosialisasi lanjutan bersama } \\
\text { Pengurus Paguyuban } \\
\text { Mubaligh-Mubalighah } \\
\text { Prenggan (PRM Prengan) }\end{array}$ \\
\hline & & 19 Maret 2020 & $\begin{array}{l}\text { Terdampak } \\
\text { Physical } \\
\text { Distancing }\end{array}$ & $\begin{array}{l}\text { Sosialisasi final bersama para } \\
\text { Ta'mir Majis dan Paguyuban } \\
\text { Mubaligh Prenggan }\end{array}$ \\
\hline 3 & $\begin{array}{l}\text { Bimtek, } \\
\text { Penyuluhan dan } \\
\text { Pendampingan }\end{array}$ & 05 April 2020 & $\begin{array}{l}\text { Terdampak } \\
\text { Physical } \\
\text { Distancing }\end{array}$ & $\begin{array}{l}\text { Komunikasi dan bimbingan } \\
\text { teknis persiapan pelatihan } \\
\text { Da'i antikorupsi mengunakan } \\
\text { WhatsApp. }\end{array}$ \\
\hline 4 & $\begin{array}{l}\text { Praktik dan } \\
\text { Demonstrasi }\end{array}$ & 10 Mei 2020 & $\begin{array}{l}\text { Terdampak } \\
\text { Physical } \\
\text { Distancing }\end{array}$ & $\begin{array}{l}\text { Pelatihan Da'i antikorupsi } \\
\text { menggunakan Google Meet. }\end{array}$ \\
\hline 5 & $\begin{array}{l}\text { Evaluasi dan } \\
\text { Monitoring }\end{array}$ & 10 Mei 2020 & $\begin{array}{l}\text { Terdampak } \\
\text { Physical } \\
\text { Distancing }\end{array}$ & $\begin{array}{l}\text { Evaluasi pelaksanaan } \\
\text { pelatihan Da'I antikorupsi } \\
\text { menggunakan Google Meet. }\end{array}$ \\
\hline
\end{tabular}




\section{HASIL DAN PEMBAHASAN}

Sebagaimana dikemukakan sejak awal bahwa pelaksanaan program pengabdian masyarakat ini dilakukan dalam situasi physical distancing akibat pandemi Covid-19. Wabah ini merupakan virus penyakit menular yang jauh lebih berbahaya dari pada H1N1 (Flu Babi), SARS, dan MERS (Guarner, 2020), (Al-mandhari, et al., 2020), sehingga pencegahannya harus lebih ketat. Saat ini, pertanggal 11 Mei 2020 pandemi Covid-19 telah menyebar ke 215 negara dengan korban sejumlah 3.976 .043 kasus dan 277.708 meningal dunia (Jung et al., 2020).

Di Indonesia pertangal 11 Mei 2020 penyebaran Covid-19 tercatat 14.265 kasus dan 991 dinyatakan meninggal dunia. Di Yogyakarta, data pertanggal 11 Mei tercatat 159 positif, 148 proses, 807 negatif, 61 sembuh dan 11 plus 7 dinyatakan meninggal dunia. Khusus di Kelurahan Prenggan Kotagede Yogyakarta yang menjadi seting pengabdian masyarakat ini berstatus zona kuning dengan 64 Orang Dalam Pengawasan (ODP), 11 Pasien Dalam Pengawasan (PDP), dan 0 Positif. Gambar 2 mernunjukkan hasil pencarian sebaran Covid-19 di Kelurahan Prenggan mengunakan aplikasi https://corona.jogjaprov.go.id/ dengan area scanner menggunakan kodepos 55172 (kode pos Prenggan Kotagede Yogyakarta).

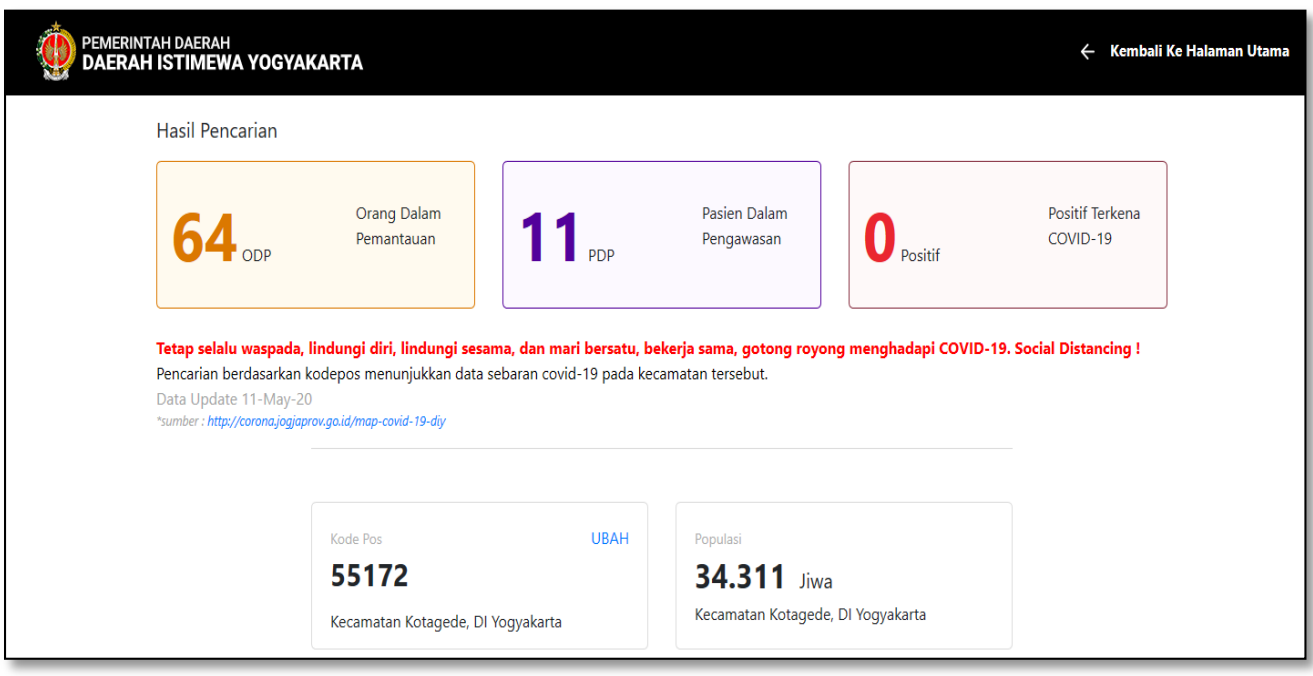

Gambar 2. Keluarahan Prenggan (Desa Antikorupsi: Zona Kuning Covid-19) Sumber: https://corona.jogjaprov.go.id/ area scanner kodepos 55172

Berdasarkan kondisi wilayah Prenggan yang termasuk siaga atau zona kuning di atas, makak wajib mematuhi UU No.6/Darurat Sipil dan Surat Edaran Gubernur DIY Nomor, 2/SE/III/ 2020 yang secara umum menghimbau dengan sangat agar seluruh rakyat Indonesia, termasuk masyarakat Prenggan Kotagede Yogyakarta harus menjalani social distancing atau isolasi diri, karantina mandiri, "dirumah saja"dengan Bekerja dari Rumah (Work From Home). Oleh karena itu, semua bentuk kegitan harus dilakukan dari rumah masing-masing, salah satunya melalui daring, termauk pelatihan Da'i antikorupsi ini. Berikut ini dikemukakan hasil pengabdian kepada masyarakat sesuai tahapan yang ditempuh. 


\section{Sosialisasi Pelatihan Da'i Antikorupsi dalam Kondisi Darurat Covid-19}

Sosialisasi pelatihan Da'i antikorupsi kepada Paguyuban Mubaligh-Mubalighah terdampak pandemi Covid-19 di Kelurahan Prenggan dilakukan pada Kamis 19 Maret 2019 di Sekretariat Pimpinan Ranting Muhammadiyah dan Aisyiyah. Tempat ini dipilih karena seluruh warga Prengan termasuk Mubaligh-Mubalighah tergabung dalam Persyarikatan Muhammadiyah. Materi sosialias pelatihan Da'i antikorupsi adalah hasil-hasil penelitian Tim Pengabdi yang mengacu pada Fikih Antikorupsi (Anwar, 2006). Gambar 2a dan 2b menunjukkan proses sosialisasi ini dilaksanakan. Berikut ini dikutipakan dialog sosialisasi pelatihan Da'i antikorupsi tersebut:

Tim : "Kami bersilaturahmi ke desa antikorupsi Kelurahan Prenggan Pengabdi bermaksud menyelenggarakan pelatihan Da'i antikorupsi kepada Mubaligh-Mubalighah di Kelurahan Prenggan, karena selama ini peran Da'i terhadap pencegahan korupsi masih sangat minim, padahal Koruptor yang Ta'at beribadah di masjid-masjid semakin banyak. Selanjutnya, mengingat kita sekarang dalam situasi terdampak physical distancing, maka kami usul agar pelatihan ini dilaksanaka secara daring menggunakan aplikasi Google Meet dan Whatsap Group."

Ketua : "Kedatangan Tim Pengaddi di Kelurahan Prenggan sangat tepat, Paguyuban karena di sini satu-satunya desa antikorupsi. Kami senang dengan Mubaligh tawaran atau ajakan ini dan baru sadar bahwa agama Islam harus mempunyai andil dalam pencegahan korupsi di Indonsia."
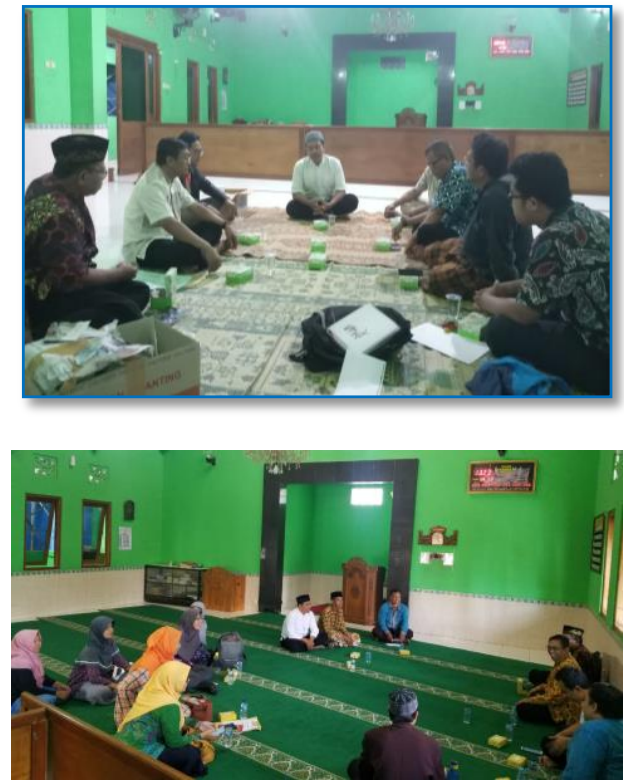

2b. Pelaksanan sosialisasi pelatihan Da'i antikorupsi

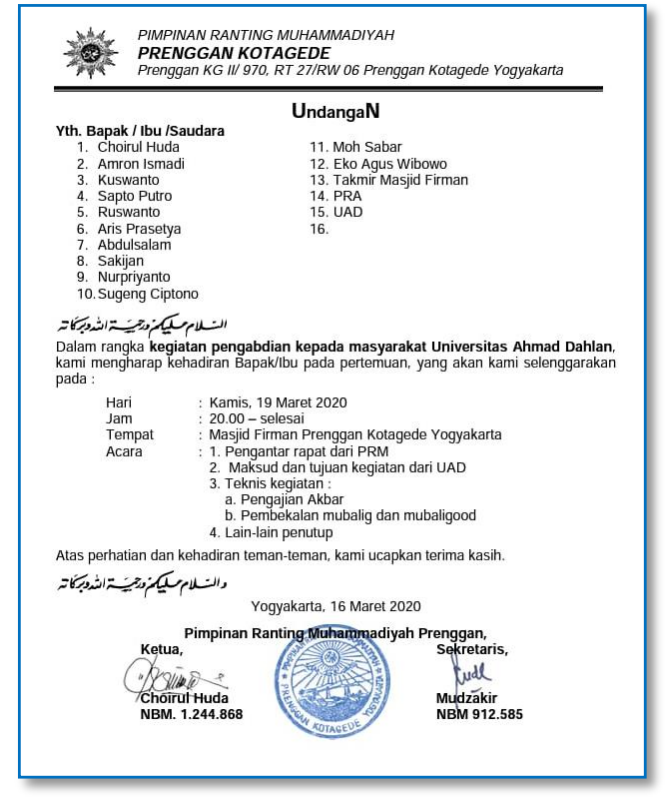

Gambar 2a. Undangan Sosialisasai Pelatihan Da'i antikorupsi oleh Mitra 
Kutipan dialog dan dokumentasi sebagaimana ditunjukkan gambar $2 \mathrm{a}$ dan $2 \mathrm{~b}$ di atas selaras dengan pripsip program pengabdian dan pemberdayaaan masyarakat, bahwa sebuah program tidak boleh dipaksakan, melainkan harus atas dasar kesepakatan diantara kedua belah pihak. Dengan demikian, dapat disimpulkan bahwa sosialisasi pelatihan daring Da'i antikorupsi bagi paguyuban Mubaligh-Mubalighah terdampak physical distancing diterima telah menjadi kesepakatan bersama.

\section{Bimbingan Teknis dan Penyuluhan Da'i Antikorupsi Secara Daring}

Sebagaimana telah disepakati bersama antara Tim Pengabdi dengan Masyarakat (Paguyuban Mubaligh-Mubalighah Prenggan), bahwa pelatihan, termasuk penyuluhan dilakukan secara daring, maka kegiatan tersebut dimulai sejak 5 April 2020, yang berarti pandemi Covid-19 belum mereda. Aplikasi yang dominan digunakan adalah WhatsApp Group (WAG). Sedangkan Google Meet pada bimtek hanya berupa simulasi untuk membekali keterampilan teknis peserta. Mekanisme pelatihan Da'i antikorupsi secara daring adalah sebagai berikut:

1) Tim Pengabdi membuat WAG yang berisi Tim Pengusul dan seluruh MubalighMubalighah Prenggan.

2) Tim Pengusul menetapkan admin WAG berserta tugasnya.

3) Admin WAG membuat peraturan, diantaranya menyepakati bahwa pelatihan daring disepakati setiap Sabtu malam Mingu sepanjang bulan April dan Mei pada pukul 19.30 sampai dengan 21.00 WIB (menyesuaikan situasi dan kondisi pandemi).

4) Sejak WAG ini dibuat, para Mubaligh/ Mubalighah diminta untuk memulai menyusun materi dakwah atau khutbah bernada antikorupsi. Panduan dalam menyusun materi dakwah antikorupsi ini dapat mengacu pada fikih antikorupsi yang akan dishare dalam WAG ini. Secara umum, materi tersebut berisi:

5) Materi da'wah antikorupsi harus mengutip: minimal satu ayat Alquran, satu hadis Rasulullah Saw, dan satu pasal dalam UU Tindak Pidana Korupsi.

6) Materi ditulis antara 400-1000 kata atau selesai dibaca dalam waktu 7-10 menit.

7) Praktik dakwah antikorupsi disarankan tidak membaca teks secara kaku.

8) Disarankan menggunakan bahasa/ retorika dakwah yang sesuai dengan audien/ jama'ah.

9) Pada waktu yang telah disepakati, Tim Pengabdi menjadi Host dalam Google Meet untuk pelaksanaan pelatihan Da'i antikorupsi dan perwakilan peserta diminta untuk mendesmonstrasikan/ praktik dakwah antikorupsi.

10)Setiap pelatihan akan dimulai seluruh peserta diharap presensi online dengan menuliskan (Nama: Da'i Antikorupsi). Admin bertugas mengklarifkasi apakah ada anggota yang belum siap-online.

11)Tim pengabdi menyampaikan muqodimah Fikih Antikorupsi, diikuti dengan uplod materi PPT, ebook (format PDF) Fikih Antikorupsi, dan satu video yang diambil dari website KPK (aclc@kpk.go.id) tentang salah satu kasus korupsi yang menjerat Pemuka Agama.

12) Peserta merespon materi yang disampaikan dengan mengajukan pertanyan atau bentuk lain.

Setelah semua peserta mengupload materi dakwah antikorupsi, maka Tim Pengabdi segera menyiapkan jadwal pelaksanaan pelatihan daring Da'i antikorupsi. Dengan 
demikian indikator keberhasilan tahap bimtek dan penyuluhan dan penyuluhan online adalah tersusunnya materi dakwah antikorupsi dari peserta. Hal ini menunjukkan adanya peningkatan kompetensi peserta atau mitra di bidang dakwah antikorupsi.

\section{Implementasi, Pendampingan dan Demonstrasi Da'wah Antikorupsi}

Setelah bimbingan teknis (bimtek), penyukuhan dan pendampingan yang telah dilakukan sejak 5 April dipandang cukup, maka implementasi pelatihan Da'i antikorupsi dilaksanakan pada hari Minggi 10 Mei 2020. Tim Pengabdi menjadi Host pada apliaksi Google Meet dengan kode: https://meet.google.com/ehu-hbcc-yiq, Host Phone: +1 347-815-1828 PIN: 105568 877\#. Kode ini dikirim ke WAG Pelatihan Da'i Antikoruspi dan peserta (Mubaligh-Mubalighah) diminta untuk gabung dalam Google Meet tersebut. Gambar 4a dan $4 \mathrm{~b}$ berikut ini merupakan pelaksanaan pelatihan Da'i antikorupsi.

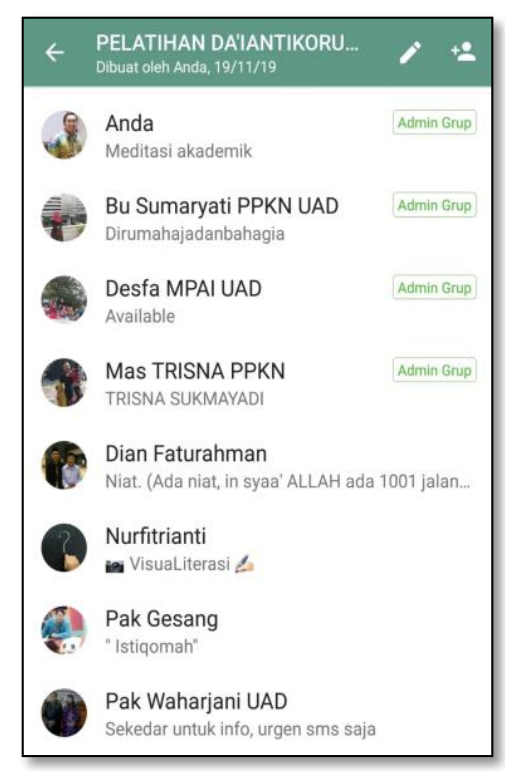

Gambar 4a. WhatsApp Group: Apliasi Pendukung Pelatihan Da'i Antikorupsi
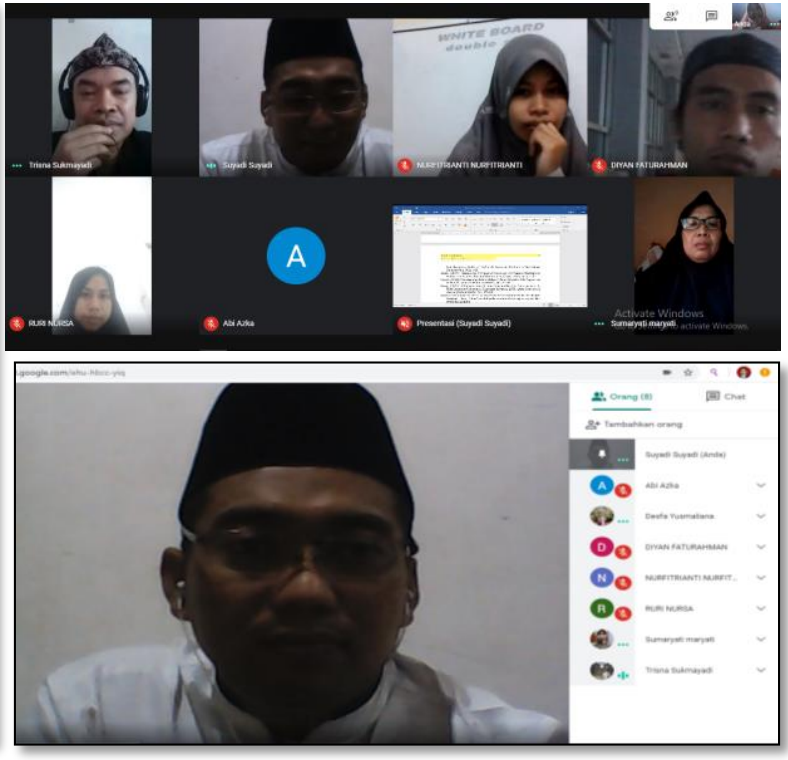

Gambar 4b. Google Meet: https://meet.google.com/ehuhbcc-yiq

Host Phone: +1 347-815-1828 PIN: 105568 877\# Aplikasi Utama Pelatihan Da'i Antikorupsi

Gambar 4a merupakan screenshoot WAG pelatihan Da'i Antikorupsi yang berfungsi sebagai aplikasi pendukung untuk komuniksi dan bimbingan teknis, sedangkan gambar $4 \mathrm{~b}$ merupakan proses pelaksanaan pelatihan Da'i antikorupsi menggunakan aplikasi Google Meet. Selanjutnya, untuk memperdalam khasanah keilmuan tentang antikorupsi, dibuka sesi dialog virtual interaktif, agar materi dakwah menunjukan kulitas yang bermutu tingi. Dalam sesi ini, terdapat pertanyan salah satu peserta yang sangat kritis:

Mubaligh : Mengapa ada orang Islam yang selama ini terlihat saleh, tekun beribadah bahkan haji berulang kali tetapi korupsi?

Pengabdi : Karena ia hanya memiliki kesalehan ritual, individual dan sosial, tetapi belum memiliki kesalehan konstitusional. Jawaban ini dikutip 
dari hasil penelitian Tim Pengusul sendiri (Suyadi \& Sutrisno, 2018);

(Suyadi, et al., 2019; Suyadi, 2019a).

Pengabdi : "Di tengah situasi darurat Covid-19 seperti sekarang ini, sebenarnya kita juga menjadi korban perilaku koruptif. Apa itu?

Mubaligh : "Ada oknum kesehatan yang menimbun masker dan hand sanitizer, sehingga masyarakat sulit memperoleh, dan jika ada harganya mahal."

Pertanyataan peserta (Mubaligh-Mubalighah) tidak hanya dijawab oleh Tim Pengusul, tetapi sesama Mubaligh boleh saling tanya dan saling jawab, sehingga terjadi "interaksi virtual." Berdasarkan kutipan dialog virtual tersebut, tampak sekali bahwa peserta (Mubaligh-Mubalighah) meninjukkan peningkatan pengetahuan tentang antikorupsi yang sangat kritis. Hal ini dibuktikan dengan pertanyaan-pertanyan aktual yang dilihat, dialami dan dirasakan dalam realitas kehidupan sosial. Di samping itu, para Da'i juga menunjukkan peningkatan keterampilan penggunaan aplikasi Google Meet yang signifikan, ditunjukkan dengan lancarnya penggunaan aplikasi ini. Mencermati dinamika interaksi virtual sepanjang proses pelatihan da'i antikorupsi tersebut, dapat dikatakan bahwa aplikasi Google Meet dan WAG dapat menjadi media pelatihan $\mathrm{Da}^{\prime} \mathrm{i}$ antikorupsi yang efektif.

Setelah sesi pendalaman materi dianggap cukup, maka sesu selanjutnya adalah praktik atau demonstrasi, yakni peserta memperagakan atau mempraktikkan dakwah antikorupsi. Dalam hal ini, mitra berinisial DF mewakili yang Da'i lainnya dalam memperagakan dakwah antikorupsi sesuai materi yang telah disusun sebelumnya. Adapun peserta lainnya membuat vidoe dakwah antikorupsi secara mandiri dan dikirim kepada WAG Tim Pengabdi.

\section{Evaluasi dan Monitoring Da'wah Antikorupsi}

Evaluasi dilakukan setelah selesai pelatihan Da'i antikorupsi melalui Google Meet selesai dilaksanakan. Setelah semua peserta atau Mubaligh-Mubalighah menyusun teks materi dakwah antikorupsi, maka tugas Tim Pengabdi adalah mengorekasi apakah sudah sesuai ketentuan atau belum. Jika belum sesuai ketentuan, maka Tim Pengabdi mendamping peserta untuk melakukan perbaikan.

Evaluasi juga dilakukan pada video praktik dakwah antikorupsi, baik berupa Khutbah Jum'at, Kultum (Kuliah Tujuh Menit), Kulsub (Kuliah Subuh), atau bentuk dakwah lainnya. Evaluasi dini didasarkan indikator minimal muatan materi dakwah antikorupsi, yakni mengutip ayat Alqura, Hadis dan salah satu pasal dalam UU Tindak Pidana Koruspi.

Hasil perbaikan materi teks dakwah antikorupsi kemudian didokumentasikan menjadi book chapter berjudul "Dakwah Antikorupsi". Buku ini kemudian diterbitkan oleh UAD Press, Anggta IKAPI dan ber-ISBN. Buku ini selanjutnya diajukan ke Kemenkumham untuk proses pengajuan Hak Cipta.

Pasca pelatihan, para Mubaligh-Mubalighah akan dimonitoring secara online dengan mengisi google form. Setiap Mubaligh-Mubalighah menjadi penceramah atau pemateri, mereka diminta untuk mengisi google form dengan melampirkan foto atau 
video. Dengan demikian, berapa kali para Mubaligh menyampaikan pesan dakwah antikorupsi dapat dipantau secara online.

Model evaluasi dan monitoring pelaksanaan yang diterapkan dalam pelatihan Da'i antikorupsi ini pada dasarnyanya mengadaptasi sistem evalusi dan monitoring yang digunakan oleh Komisi Pemberantasan Korupsi (KPK). Hal ini tidak berlebihan karena tiga dari empat Tim Pengabdi adalah Penyuluh Antikorupsi yang tersertfikasi secara resmi oleh KPK. Dengan demikian, pelatihan Da'i antikorupsi bagi para MubalighMubalighah terdampak social distancing di Kelurahan Prenggan (desa antikoruspi) Kotagede Yogyakarta merupakan upaya "kepanjangan" KPK untuk melibatkan Da'i yang berbasis pada Masjid dalam pencegahan korupsi di Indonesia.

\section{SIMPULAN}

Pelatihan Da'i antikorupsi bagi para Mubaligh-Mubalighah terdampak physical distanciang di Kelurahan Prenggan (desa antikorupsi) Kotagede Yogyakarta merupakan upaya terstruktur dan sistematis untuk melibatkan Da'i-Da'iyah atau MubalighMubalighah dalam pencegahan korupsi. Pelatihan ini dapat meningkatkan kompetensi para Da'i-Da'iyah atau Mubaligh-Mubalighah dalam tiga aspek, yakni peningkatan pemahaman tentang Fikih Antikorupsi, peningkatan keterampilan retorika dakwah di tengah pandemi Covid-19, dan peningkatan keterampilan dalam memanfaatkan kemajuan teknologi informasi untuk kepentingan dakwah antikorupsi, khususnya aplikasi Google Meet. Sistem evaluasi dan monitoring yang diadaptsi dari KPK menjadikan pelatihan da'i antikorupsi ini berdampak jangka panjang, yakni penyebarluasan materi dakwah antikorupsi lebih masif oleh para MubalighMubalighah atau Da'i-Da'iyah antikorupsi.

\section{Ucapan Terima Kasih}

Tim Pengabdi mengucapkan terimkasih kepada Kementerian Pendidikan dan Kebudayaan, Direktorat Jenderal Riset, Teknologi dan Pendidikan Tinggi atas pendanaan yang diberikan melalui hibah kompetitif Multiyears skim Program Pengabdian Masyarakat Unggulan Perguruan Tinggi guna mewujudkan Kelurahan Prengan sebagai Desa Antikorupsi Berbasis Masjid yang dibina oleh Universitas Ahmad Dahlan.

\section{REFERENSI}

Ahmad Muhtadi, M. L. (2017). ReboisasibBerbasis PAR oleh kelompok tani hutan (Pendampingan riset aksi partisipatoris di Desa Jembul Kecamatan Jatirejo Kabupaten Mojokerto) Martinus Legowo.

Al-Mandhari, A., Samhouri, D., Abubakar, A., \& Brennan, R. (2020). Coronavirus disease 2019 outbreak: preparedness and readiness of countries in the Eastern Mediterranean Region. East Mediterr Health Journal, 26(2), 136-137. https://doi.org/10.1038/s41586-020-2012-7 
Anwar, S. (2006). Fikih anti korupsi perspektif ulama Muhammadiyah. Yogyakarta: Majelis Tarjih dan Tajdid Pimpinan Pusat Muhammadiyah.

Asroni, A., \& Yusuf, M. (2016). Pesantren and anti-corruption movement: The significance of reconstruction of pesantren education system for eradicating corruption. Cendekia: Jurnal Kependidikan dan Kemasyarakatan, 12(1), 1-13. https://doi.org/10.21154/cendekia.v12i1.360

Atabekova, A., Belousov, A., \& Shoustikova, T. (2015). Web 3.0-based non-formal learning to meet the third millennium education requirements: University Students' perceptions. Procedia-Social and Behavioral Sciences, 214(June), 511-519. https://doi.org/10.1016/j.sbspro.2015.11.754

Boyinbode, O. K., Agbonifo, O. C., \& Ogundare, A. (2017). Supporting Mobile Learning with WhatsApp based on Media Richness. Circulation in Computer Science, 2(3), 37-46. https://doi.org/10.22632/ccs-2017-251-89

Cuaca Dharma, H. R., Asmarani, D., \& Dewi, U. P. (2017). Basic Japanese Grammar and Conversation e-learning through Skype and Zoom Online Application. Procedia Computer Science, 116, 267-273. https://doi.org/10.1016/j.procs.2017.10.055

Feni Qoriroh, M. M. K. S. (2016). Partisipasi aktivis saya perempuan anti korupsi (SPAK) dalam upaya pendidikan antikorupsi di Surabaya. Kajian Moral Dan Kewarganegaraan, 3(4), 1279-1291.

Freedman, D. O. (2020). Isolation, quarantine, social distancing and community containment: Pivotal role for old-style public health measures in the novel coronavirus (2019-nCoV) outbreak. Journal of Travel Medicine, 1(1), 1-4. https://doi.org/10.1093/jtm/taaa020

Guarner, J. (2020). Three emerging coronaviruses in two decades the story of SARS, MERS, and Now COVID-19. American Society for Clinical Pathology, 153(1), 420-421. https://doi.org/10.1093/AJCP/AQAA029

Jain, J., \& binti Abd Rahman, N. (2016). Learning beyond the walls: the role of WhatsApp groups. In A. N. Luaran J., Sardi J., \& Aziz A. Envisioning the Future of Online Learning (pp. 447-457). Singapore: Springer.

Jati, B. J. B., \& Putra, G. R. A. (2020). Optimalisasi upaya pemerintah dalam mengatasi pandemi covid 19 sebagai bentuk pemenuhan hak warga negara. SALAM: Jurnal Sosial dan Budaya Syar-i, 7(5), 473-484.

Jung, S., Akhmetzhanov, A. R., Hayashi, K., Linton, N. M., Yang, Y., Yuan, B., Kobayashi, T., Kinoshita, R., \& Nishiura, H. (2020). Real-time estimation of the risk of death from novel coronavirus (COVID-19) infection: Inference using exported cases. Journal of Clinical Medicine, 523(9), 1-10.

Kamal, M., \& Arifin, M. Y. (2019). The community role in prevention and eradication of corruption. Varia Justicia, 15(2), 51-58.

Mulyono, S. P. (2014). Sinergitas penyelengggaraan pemerintah desa pasca pemberlakuan UU no. 6 tahun 20145 tentang desa. $M M H, 43(3)$, 438-444. 
Rabi, M., \& Nurhidayati, S. (2018). Pengembangan model pembangunan budaya antikorupsi berbasis keluarga di Kelurahan Prenggan, Kota Yogyakarta. Integritas, 4(1), 145-170.

Rahman, F., Baidhowi, A., \& Agnesia, R. (2018). Pola jaringan korupsi di tingkat pemerintah desa (Studi kasus korupsi DD dan ADD tahun 2014-2015 di Jawa Timur). Integritas, 4(1), 29-56.

Romziatussa'adah. (2014). Pemberantasan korupsi perspektif hukum pidana Islam. Nurani, 14(1), 119-156.

Sohrabi, C., Alsafi, Z., Neill, N. O., Khan, M., Kerwan, A., Al-jabir, A., Iosifidis, C., \& Agha, R. (2020). World Health Organization Declares Global Emergency: A Review of the 2019Novel Coronavirus (COVID-19). International Journal of Surgery, 76(2), 7176. https://doi.org/10.1016/j.ijsu.2020.02.034

Susanti, L., Mochtar, Z. A., Madril, O., \& Ravizki, E. N. (2016). School of Integrity (SOI), dari sekolah untuk generasi antikorupsi: Program pengembangan metode penanaman nilai-nilai antikorupsi di SMA Negeri 2 Yogyakarta. In Jabrohim, \& R. R. S. Sudaryani (Eds.), Pemanfaatan IPTEKS dalam Membangun Desa Mandiri dan Religius, (pp. 161-168). Yogyakarta: Lembaga Pengabdian kepada Masyarakat Universitas Ahmad Dahlan.

Sukoco, B. (2015). Panduan madrasah anti korupsi. Yogyakarta: Suara Muhammadiyah.

Suyadi, Sumaryati, Hastuti D., Saputro A. D. (2020). Early childhood eeducation teachers' perception of the integration of anti-corruption education into Islamic religious education in Bawean Island Indonesia. Elementary Education Online, 19(3), 1703-1714. https://doi.org/10.17051/ilkonline.2020.734838

Suyadi, Sumaryati, Hastuti D., (2019). Anticorruption Education Insertion in Islamic Religious Learning In The Umar Mas'ud Kindergarten of Bawean Island Indonesia. International Journal for Innovation Education and Research, 7(10), 771-783.

Suyadi, Sumaryati, Hastuti D., Yusmaliana D., Rafika D. M. (2019). Constitutional Piety: The Integration of Anti-Corruption Education into Islamic Religious Learning Based on Neuroscience. J-PAI: Jurnal Pendidikan Agama Islam, 6(1), 38-46. https://doi.org/10.18860/jpai.v6i1.8307

Suyadi. (2018a). Kisah (Storytelling) pada pembelajaran anak usia dini dalam kajian neurosains pendidikan Islam. Jurnal Ilmiah Islam Futura, 18(1), 52-74.

Suyadi. (2018b). Pendidikan Islam anak usia dini dalam perspektif neurosains: Robotik akademik dan saintifik. Edukasia: Jurnal Penelitian Pendidikan Islam, 13(2), 231-262. https://doi.org/http://dx.doi.org/10.21043/edukasia.v13i2.3255

Suyadi. (2019a). Hybridization of Islamic education and neuroscience: Transdisciplinary studies of 'aql in the Quran and the brain in neuroscience. Dinamika Ilmu, 19(2), 237249. https://doi.org/doi: http://doi.org/10.21093/di.v19i2.1601

Suyadi, S. (2019b). Integration of anti-corruption education (PAK) In Islamic religious education (PAI) with neuroscience approach (Multi-case study in brain friendly PAUD: I Sleman Kindergarten Yogyakarta). Inferensi: Jurnal Penelitian Sosial Keagamaan, 12(2), 307-330. https://doi.org/10.18326/INFSL3.V12I2.307-330 
Suyadi, \& Sutrisno. (2018). A Genealogycal study of Islamic education science at the Faculty of Ilmu Tarbiyah dan Keguruan UIN Sunan Kalijaga. Al-Jami'ah, 56(1), 29-58. https://doi.org/10.14421/ajis.2018.561.29-58

Tom, E. J., \& Bamgboye, P. O. (2017). The Role of religion in combating corruption: The Nigerian. International Journal of Social Sciences, 11(2), 128-142.

Urban, H. (2005). Spiritual capital, academic capital and the politics of scholarship: A Response To Bradford verter. Method \& Theory in the Study of Religion, 17(2), 166-175.

Verter, B. (2003). Spiritual capital: Theorizing religion with Bourdieu. Sociological Theory, 21(2), 150-174.

Waharjani. (2016). Manajemen masjid. Yogyakarta: UAD Press.

Waharjani. (2018a). Pelatihan imam dan khatib. Yogyakarta: LPPM-UAD.

Waharjani. (2018b). Pelatihan mubaligh. Yogyakarta: LPPM-UAD.

Warf, B. (2016). Global geographies of corruption. GeoJournal, 81(5), 657-669. https://doi.org/10.1007/s10708-015-9656-0

Waskito, M. N., \& Pambudi, D. I. (2018). Penanaman nilai antikorupsi siswa SD melalui pendidikan keluarga di Kampung Prenggan. Fundamental Pendidikan Dasar, 1(3), 173182.

Widodo, S. H. (2019). Millennialization of Islamic Education Based on Neuroscience in The Third Generation University in Yogyakarta Indonesia. Qudus International Journal of Islamic Studies, 7(1), 173-202. https://doi.org/10.21043/qijis.v7i1.4922

Xixiong X., Yaoqin Li., Xing L., W. G. (2017). Does religion matter to corruption? Evidence from China. China Economic Review, 42(1), 34-49.

Yeary, K. H. K., Ounpraseuth, S., \& Moore, P. (2012). Religion, social capital, and health. Review of Religious Research, 54(3), 331-347.

\section{Copyright and License}

This is an open access article distributed under the terms of the Creative Commons Attribution 4.0 International License, which permits unrestricted use, distribution, and reproduction in any medium, provided the original work is properly cited. (C) 2020 Suyadi, Waharjani, Sumaryati, Trisna Sukmayadi. 